\title{
Corrigendum: Signaling Pathways Regulating Thermogenesis
}

\author{
Chihiro Tabuchi and Hei Sook Sul * \\ Department of Nutritional Sciences and Toxicology, University of California, Berkeley, Berkeley, CA, United States
}

Keywords: thermogenesis, brown adipose tissue, browning/beiging, $\beta 3$-adrenergic signaling, UCP1, insulin/IGF1 signaling, thyroid hormone, TGF $\beta$ superfamily

\section{A Corrigendum on}

Signaling Pathways Regulating Thermogenesis

By Tabuchi C and Sul HS (2021). Front. Endocrinol. 12:595020. doi: 10.3389/fendo.2021.595020

\section{OPEN ACCESS}

Edited and reviewed by: Jiqiu Wang, Shanghai Jiao Tong University,

China

*Correspondence: Hei Sook Sul hsu@berkeley.edu

Specialty section: This article was submitted to Cellular Endocrinology, a section of the journal Frontiers in Endocrinology

Received: 21 April 2021 Accepted: 02 June 2021 Published: 22 June 2021

Citation:

Tabuchi C and Sul HS (2021) Corrigendum: Signaling Pathways Regulating Thermogenesis.

Front. Endocrinol. 12:698619. doi: 10.3389/fendo.2021.698619
In the original article, there were errors in Figures 1 and 2. In Figure 1, IRF4 had to be removed and the order of the transcription factors had to be reorganized during this correction. In Figure 2, SMAD2 needs to be removed. The corrected Figures $\mathbf{1}$ and $\mathbf{2}$ are below.

In the original article, there were errors in the text. IRF4 needed to be replaced with PGC1 $\alpha$ as a downstream target of $\mathrm{p} 38$. PGC1 $\alpha$ and DIO needed to be removed as downstream targets of CREB, due to insufficient research.

A correction has been made to the section $\boldsymbol{\beta}_{\mathbf{3}}$-Adrenergic Signaling, the second paragraph:

"p38, a MAP kinase, phosphorylates multiple transcription factors/coregulators, including ATF2 and PGC1 $\alpha$, both of which promote UCP1 transcription (22). In addition, we recently found that $\mathrm{ZC} 3 \mathrm{H} 10$, previously known to bind RNA, is phosphorylated by p38 upon cold, activating the thermogenic gene program in adipocytes (17). Specifically, ZC3H10 binds a distal upstream region of the UCP1 promoter for transcriptional activation. ZC3H10 also activates NRF1 and TFAM, which facilitate mitochondrial biogenesis to increase thermogenic capacity of adipocytes. Thus, transgenic mice overexpressing ZC3H10 exhibited increased oxygen consumption, higher BAT temperature and reduced body weight while $\mathrm{ZC} 3 \mathrm{H} 10$ knockout mice displayed decreased oxygen consumption, lower BAT temperature and increased body weight. PGC1 $\alpha$, a downstream target of p38, serves as co-activator for PPAR $\gamma$ and NRF1 to induce expression of UCP1 and TFAM, respectively $(27,28)$. CREB was also shown to bind to the proximal promoter of UCP1 to potentially activate the transcription."

The authors apologize for these errors and state that this does not change the scientific conclusions of the article in any way. The original article has been updated. 


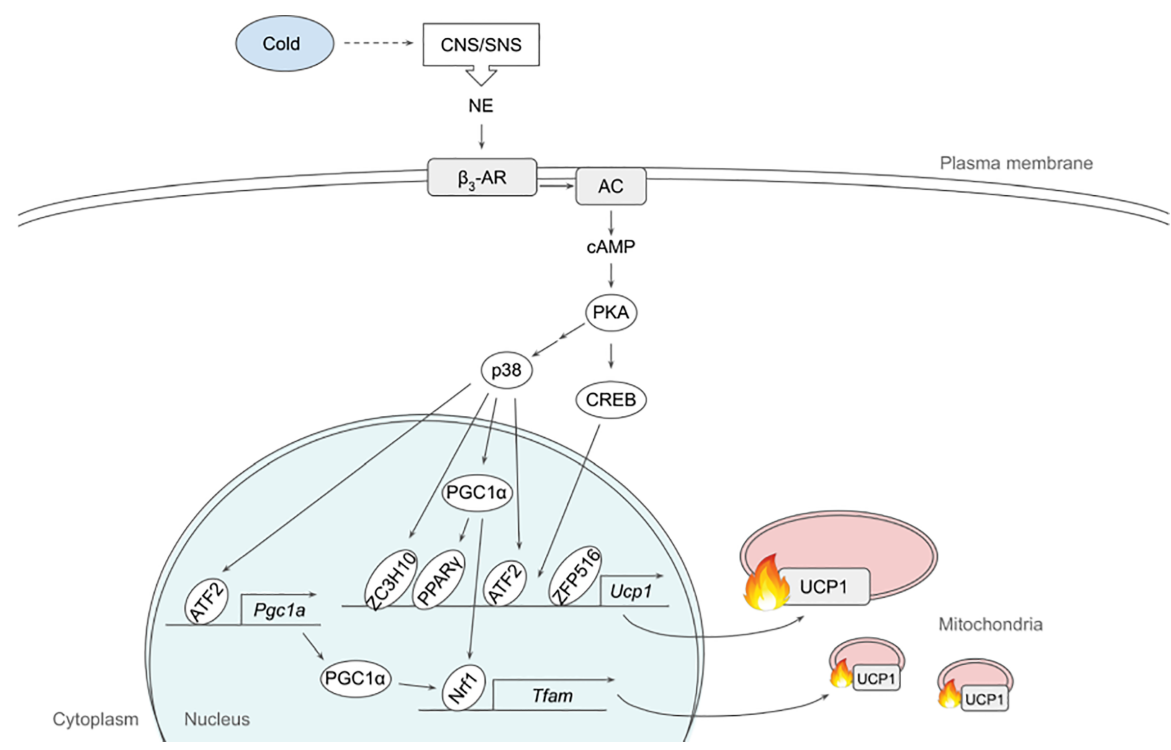

FIGURE 1 | Schematic model of $\beta_{3}$-adrenergic signaling pathway that promotes thermogenesis in adipocytes. Cold stimulates CNS/SNS to secrete NE that binds $\beta_{3}-A R$, which then activates AC producing CAMP. CAMP in turn activates PKA that has a variety of downstream targets, including transcription factors to upregulate thermogenic gene expression. See text for details. AC, adenylate cyclase; ATF2, activating transcription factor 2; $\beta_{3}$-AR, $\beta_{3}$-adrenergic receptor; CNS, central nervous system; CREB, CAMP response-element binding protein; ETC, electron transport chain; FFA, free fatty acid; IRF4, interferon regulatory factor 4; NE, norepinephrine; NRF1, nuclear respiratory factor 1; PGC1 $\alpha$, peroxisome proliferator activated receptor $\gamma$ coactivator $\alpha$; PKA, protein kinase A; PPAR $\gamma$, peroxisome proliferator activated receptor $\gamma$; SNS sympathetic nervous system; TCA, tricarboxylic acid; TFAM, mitochondrial transcription factor A; UCP1, uncoupling protein 1; ZC3H10, zinc finger CCCH-type containing 10; ZFP516, zinc finger protein 516.

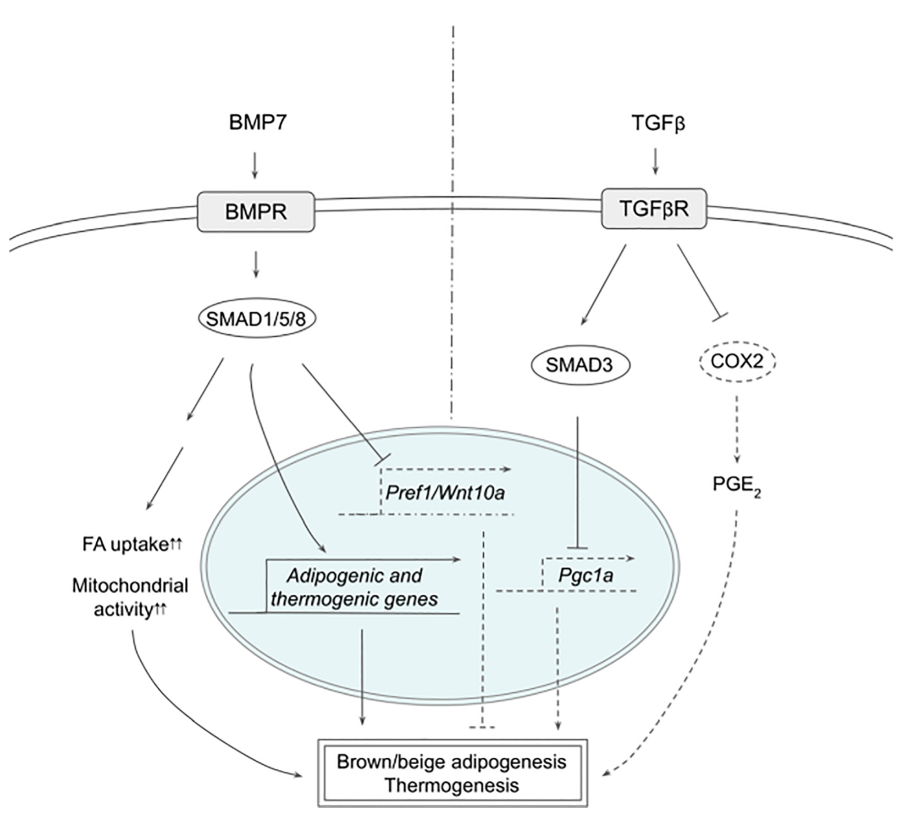

FIGURE 2 | Schematic models of BMP7 and TGF $\beta$ signaling pathways in thermogenesis. BMP7 binds TGF $\beta$, which activates SMAD1/5/8, leading to expression of adipogenic and thermogenic genes as well as suppression of Pref1 and Wnt10a in precursor cells to promote brown and beige adipogenesis. In mature adipocytes, BMP7 signaling increases FA uptake and mitochondrial activity, resulting in enhanced thermogenesis. TGF $\beta$ activates SMAD2/3 that suppresses PGC1 $\alpha$ expression and COX2/PGE2 pathway to reduce thermogenesis. See text for details. BMP7, bone morphogenetic protein 7; COX2, cyclooxygenase 2; FA, fatty acid; PGC1 $\alpha$, peroxisome proliferator activated receptor $\gamma$; PGE2, prostaglandin E2; PREF1, preadipocyte factor 1; SMAD, mothers against decapentaplegic homolog; T $\beta R 1$, TGF $\beta$ receptor 1; TGF $\beta$, Transforming growth factor beta; TGF $\beta$ R, TGF $\beta$ receptor; WNT10a, Wnt family member $10 \mathrm{~A}$. 


\section{REFERENCES}

17. Yi D, Dempersmier JM, Nguyen HP, Viscarra JA, Dinh J, Tabuchi C, et al. Zc3h10 Acts as a Transcription Factor and Is Phosphorylated to Activate the Thermogenic Program. Cell Rep (2019) 29(9):2621-33.e4. doi: 10.1016/ j.celrep.2019.10.099

22. Yi D, Nguyen HP, Sul HS. Epigenetic Dynamics of the Thermogenic Gene Program of Adipocytes. Biochem J (2020) 477(6):1137-48. doi: 10.1042/ BCJ20190599

27. Cao W, Daniel KW, Robidoux J, Puigserver P, Medvedev AV, Bai X, et al. p38 Mitogen-Activated Protein Kinase Is the Central Regulator of Cyclic
AMP-Dependent Transcription of the Brown Fat Uncoupling Protein 1 Gene. Mol Cell Biol (2004) 24(7):3057-67. doi: 10.1128/MCB.24.7.3057-3067.2004 28. Liang H, Ward WF. PGC-1alpha: A Key Regulator of Energy Metabolism. Adv Physiol Educ (2006) 30(4):145-51. doi: 10.1152/advan.00052.2006

Copyright (C) 2021 Tabuchi and Sul. This is an open-access article distributed under the terms of the Creative Commons Attribution License (CC BY). The use, distribution or reproduction in other forums is permitted, provided the original author(s) and the copyright owner(s) are credited and that the original publication in this journal is cited, in accordance with accepted academic practice. No use, distribution or reproduction is permitted which does not comply with these terms. 